Article

\title{
Impact of Urban Surface Characteristics and Socio-Economic Variables on the Spatial Variation of Land Surface Temperature in Lagos City, Nigeria
}

\author{
DMSLB Dissanayake ${ }^{1,2, *(\mathbb{D})}$, Takehiro Morimoto ${ }^{3}$, Yuji Murayama ${ }^{3}(\mathbb{1}$, \\ Manjula Ranagalage ${ }^{1,2, *(1)}$ and Hepi H. Handayani ${ }^{1,4}$ (1) \\ 1 Graduate School of Life and Environmental Sciences, University of Tsukuba, 1-1-1, Tennodai, Tsukuba, \\ Ibaraki 305-8572, Japan; hepihh@geoenv.tsukuba.ac.jp \\ 2 Department of Environmental Management, Faculty of Social Sciences and Humanities, Rajarata University \\ of Sri Lanka, Mihintale 50300, Sri Lanka \\ 3 Faculty of Life and Environmental Sciences, University of Tsukuba, 1-1-1, Tennodai, Tsukuba, \\ Ibaraki 305-8572, Japan; tmrmt@geoenv.tsukuba.ac.jp (T.M.); mura@geoenv.tsukuba.ac.jp (Y.M.) \\ 4 Geomatics Department, Institut Teknologi Sepuluh Nopember, Campus ITS Sukolilo, Surabaya, \\ East Java 60111, Indonesia \\ * Correspondence: dissanayakedmslb@gmail.com or s1730220@u.tsukuba.ac.jp (D.D.); \\ manjularanagalage@gmail.com or s1630230@u.tsukuba.ac.jp (M.R.); Tel.: +81-029-853-4211 (D.D. \& M.R.)
}

Received: 13 November 2018; Accepted: 12 December 2018; Published: 20 December 2018

\begin{abstract}
The urban heat island (UHI) and its consequences have become a key research focus of various disciplines because of its negative externalities on urban ecology and the total livability of cities. Identifying spatial variation of the land surface temperature (LST) provides a clear picture to understand the UHI phenomenon, and it will help to introduce appropriate mitigation technique to address the advanced impact of UHI. Hence, the aim of the research is to examine the spatial variation of LST concerning the UHI phenomenon in rapidly urbanizing Lagos City. Four variables were examined to identify the impact of urban surface characteristics and socio-economic activities on LST. The gradient analysis was employed to assess the distribution outline of LST from the city center point to rural areas over the vegetation and built-up areas. Partial least square (PLS) regression analysis was used to assess the correlation and statistically significance of the variables. Landsat data captured in 2002 and 2013 were used as primary data sources and other gridded data, such as PD and FFCOE, were employed. The results of the analyses show that the distribution pattern of the LST in 2002 and 2013 has changed over the study period as results of changing urban surface characteristics (USC) and the influence of socio-economic activities. LST has a strong positive relationship with NDBI and a strong negative relationship with NDVI. The rapid development of Lagos City has been directly affected by conversion more green areas to build up areas over the time, and it has resulted in formulating more surface urban heat island (SUHI). Further, the increasing population and their socio-economic activities including industrialization and infrastructure development have also caused a significant impact on LST changes. We recommend that the results of this research be used as a proxy tool to introduce appropriate landscape and town planning in a sustainable viewpoint to make healthier and livable urban environments in Lagos City, Nigeria.
\end{abstract}

Keywords: LST; urban surface characteristics; socioeconomic variables; urban heat island; gradient analysis; partial least square (PLS) regression; Lagos City 


\section{Introduction}

As elucidated by the United Nations Development Program (UNDP) 2016, cities have occupied $0.51 \%$ of the land area out of the total in the world [1]. However, the socio-economic footprints of the cities are much larger than the rural area [1]. They provide livelihood opportunities and social mobility possibilities not found in other areas. As a result, urbanization has bloomed over the past decades, and the global urban population crossed over the global rural population in 2007 [2]. After this turning point, the highest population growth has been reported in urban areas, and it was predicted that $60 \%$ and $66 \%$ of the global population would be accommodated in cities in 2030 and 2050, respectively [1,2]. Several decades ago more developed regions were reported from the largest urban agglomerations, but nowadays they are founded by the fastest-growing cities in developing regions located in Asia and Africa [2]. Further, World Urbanization Prospect [2] stated that Africa and Asia show rapid urbanization trend. At present, the urban fraction is increasing by $1.5 \%$ in Africa and $1.1 \%$ in Asia [2].

Urbanization provides a positive development for the population, but it also has negative consequences $[3,4]$ for the environment, such as the urban heat island (UHI), high population density, emission of greenhouse gasses (GHG), air pollution, and high demand for energy $[5,6]$. Changing the composition of the urban land structure and transforming the naturally vegetated land into the built-up area have been mainly caused by the formation of the UHIs [6,7]. Similarly, other anthropocentric factors, such as industrial activities, transportation, emission of $\mathrm{CO}_{2}$, and energy consumption [8], have affected an increase in the magnitude of UHIs in both day and night [9]. UHI was first accounted by Luke Howard in 1818 as a phenomenon of the city fraction denoting a higher temperature than the surrounding rural area [10-12]. Due to the negative impact of UHI in both social and environmental variables, the UHI occurrence became a significant research interest in the urban climatology and urban planning field in the middle of the 20th century [11,12]. There are two types of UHI studies, (i) atmospheric UHI (AUHI) that are calculated by air temperature, and (ii) surface UHI (SUHI), calculated by land surface temperature and appropriate for assessing spatial variation of temperature in a large area during different periods [8,12].

Previous SUHI studies have evidenced that various kinds of methods and techniques have been facilitated to study the spatial variation of SUHI around the world. Among them, the researches which is combing with geo-informatics were popular than others [11-13]. The built-up index (NDBI) and the vegetation index (NDVI) of normalized difference are frequently used as spectral indices for examining the urban surface characteristic (USC) on SUHI $[11,13,14]$. Moreover, these two spectral indices can also be derived from RS data and alternative indicators for land use and land cover [15]. As explained above, socio-economic variables play an extensive role for the formation of SUHI directly and indirectly, and the past studies also emphasized that importance of usages of the socio-economic variables including emission of GHG and population density (PD) on SUHI studies [11]. Additionally, gradient analysis was facilitated to study the variation of LST, Built-up areas and green surface (GS) from the city center to the rural area. Scatter plots and partial least square regression analysis were performed to assess the correlation and statistical significance of the variables.

Regarding this context, the authors focus Lagos City as a research field in this study. Lagos City is the landmark of the Federal Republic of Nigeria and the second most populous and fast-growing city in Africa $[5,8]$. Lagos was developed as a port city since the colonial period, and it was developed after the petroleum booming between 1970 and 1980 [16,17]. The population of Lagos City was 4.78 million in 1990; it was 12.61 million in 2014. Is predicted to become 24.23 million by 2030 [2]. Similarly, a rank of urban agglomerations increased rapidly from 19 to 33 million between 1990 and 2014 [2]. As demonstrated by the past research, some environmental and socio-economic variables are prominent for SUHI in Lagos City. $\mathrm{CO}_{2}$ emission by fossil fuel has caused the increase of temperature and air pollution in Lagos metropolis [18]. Demand for energy has also increased remarkably in the past two decades in Lagos City $[8,19]$. The naturally vegetated land which was transferred into built-up was approximately 400,000 ha per year. It is affected by urbanization and related economic activities in Nigeria [20]. However, a few SUHI studies have been conducted in Lagos metropolis in 
the past couple of years $[5,8,20,21]$. Keeping a view of the above aspect, the objective of this research is to inspect the impact of urban surface characteristics and socioeconomic variables on the spatial variation of LST. The output of this study will be able to use as the proxy tool for city development and to reach the goal of sustainability in Lagos City.

\section{Materials and Methods}

\subsection{Study Area: Lagos City, Nigeria}

Lagos, the main city of Nigeria, is geographically located in the south-western region from $3.00^{\circ} \mathrm{E}$ to $3.42^{\circ} \mathrm{E}$ longitude and from $6.22^{\circ} \mathrm{N}$ to $6.42^{\circ} \mathrm{N}$ latitude in the Lagos State, sub-Saharan Africa. It is a famous coastal city, and the Atlantic coastline is the southern boundary of the city. It has categorized as the seventh biggest city in the world [5], and it has 20 local government areas (LGA). Among them, 16 LGA have been categorized as high-density region [5]. City Hall of Lagos is considered as the city center, and representing $100 \mathrm{~km} \times 100 \mathrm{~km}$ geographical area with $50 \mathrm{~km}$ radius from the city center (Figure 1).


Figure 1. Location of Lagos City; (a) map of the African continent [22]; (b) map of Nigeria with Lagos City [23]; and (c) Landsat-8 image with gradient zones in a false color composite (band 5,4,3) (18 December 2013) [24].

The Lagos State belongs to the vegetated tropical zone and consists of rainforest, mangrove swamp, and freshwater swamp [8]. It consists of a tropical equatorial climate and is characterized by high rainfall and temperature. The rainfall pattern is mainly characterized in two seasons, (i) the wet (April to October) reports average annual rainfall of approximately $1657 \mathrm{~mm}$ by the southwest wind blowing from the Atlantic Ocean, and (ii) the dry period (November to March) is the prevailing northeast wind that takes dry air from the Sahara Desert [5,8]. 


\subsection{Data Description and Processing: Satellite Images}

United States Geological Survey (USGS) website [24] was used to download the Multi-temporal satellite data captured in the dry season. Minimum cloud cover $(<10 \%)$ or cloud-free images were selected, and two images were projected into WGS84/UTM 31N to make a stable spatial analysis environment. The whole study area belongs to path 55 and row 191. Comprehensive information relevant to two sensors were summarized to Table 1.

Table 1. Experimental data collection.

\begin{tabular}{lll}
\hline Sensor & Landsat-7 ETM+ & Landsat-8 OLI/TIRS \\
\hline Sensor ID & LE71910552002362EDC00 & LC81910552013352LGN01 \\
\hline Temporal resolution & 12 December 2002 & 18 December 2013 \\
\hline Time (GTM) & $09: 51: 17$ & $10: 04: 25$ \\
\hline
\end{tabular}

In raw Landsat data, each pixel has consisted with a digital number (DN) value that corresponds to a raw measure acquired by the sensor. In order to determine the LST from images, the DN should be transformed into physical quantities $[25,26]$. Before processing the two Landsat datasets, radiometric calibration and atmospheric correction were performed in the processing, and two approaches were completed [25].

(1) First step: Digital numbers of thermal bands have been changed to the atmosphere brightness temperature expressed in degree of Kelvin. Thermal infrared bands of both Landsat-7 ETM+ (Band 6) and Landsat-8 TIRS (Band 10) were converted to top of atmosphere (TOA) radiances using the radiance rescaling factors given by metadata file of Landsat Science Data Users Handbook [27,28]. TOA reflectance can eliminate the cosine effect at dissimilar solar zenith angles because of the time change among data obtains and modifies for the difference in the earth-sun distance among different data capturing times [26].

(a) In case of Landsat-7 ETM+:

$$
L \lambda=\left[\frac{L M A X_{\lambda}-L M I N_{\lambda}}{Q_{c a l \text { max }}-Q_{\text {cam min }}}\right]\left(Q_{\text {cal }}-Q_{\text {cal min }}\right)+L M I N_{\lambda}
$$

where $L_{\lambda}$ is the spectral radiance at wavelength $\lambda$ at the sensor's aperture $\left[\mathrm{W} /\left(\mathrm{m}^{2} \mathrm{sr} \mu \mathrm{m}\right)\right] ; L M A X_{\lambda}$ is spectral radiance corresponding to $Q_{\text {cal max }}(\mathrm{DN}=255) ; L M I N_{\lambda}$ is spectral radiance corresponding to $Q_{\text {cal min }}(\mathrm{DN}=0) ; Q_{\text {cal min }}\left(\mathrm{W} /\left(\mathrm{m}^{2} \mathrm{sr} \mu \mathrm{m}\right)\right) ; Q_{\text {cal max }}$ is the max quantized calibrated pixel value corresponding to $L M A X_{\lambda}(\mathrm{DN}) ; Q_{c a l}$ min is the min quantized adjusted pixel value corresponding to $L_{M I N}(\mathrm{DN})$; and $Q_{c a l}$ is the quantized adjusted pixel value (DN) [26].

(b) In the case of Landsat-8 TIRS,

$$
L_{\lambda}=M_{L} * Q_{c a l}+A_{L}
$$

where $L_{\lambda}$ is the spectral radiance $\left(\mathrm{W} /\left(\mathrm{m}^{2} \mathrm{sr} \mu \mathrm{m}\right)\right) ; M_{L}$ is radiance multiplicative scaling factor from the metadata; $A_{L}$ is radiance additive scaling factor for the metadata, and $Q_{c a l}$ is L1 pixel value in DN [29].

Then, the DN of the thermal bands of both Landsat-7 ETM and Landsat-8 TIRS was transformed to the brightness temperature by Equation (3):

$$
T_{b}=\frac{K_{2}}{\ln \left[\frac{K_{1}}{L_{\lambda}}+1\right]}
$$

where $T_{b}$ is TOA Brightness Temperature, in Kelvin; $l n$ is the natural logarithm; $L_{\lambda}$ is the spectral radiance $\left(\mathrm{W} /\left(\mathrm{m}^{2}{ }^{*} \mathrm{sr} * \mu \mathrm{m}\right)\right)$, and $K_{1}$ and $K_{2}$ are constants specified in the Landsat metadata for both Landsat-7 ETM+ and Landsat-8 TIRS [27,28]. 
(2) Second step: dark object subtraction (DOS) method was incorporated to multispectral image data of both Landsat-7 ETM+ and Landsat-8 OLI $[27,28]$.

(a) In case of Landsat-7 ETM+:

$$
\rho_{\lambda}=\frac{\pi * L_{\lambda} * d^{2}}{\operatorname{ESUN}_{\lambda} * \cos \theta_{s}}
$$

where $\rho_{\lambda}$ is the planetary TOA reflectance; $\pi$ is the mathematical constant equal to $\sim 3.14159 ; L_{\lambda}$ is the spectral radiance at the sensor's aperture $\left(\mathrm{W} /\left(\mathrm{m}^{2} \mathrm{sr} \mu \mathrm{m}\right)\right) ; d$ is the Earth-Sun distance; $E S U N_{\lambda}$ is the mean of exoatmospheric solar irradiance $\left(\mathrm{W} /\left(\mathrm{m}^{2} \mu \mathrm{m}\right)\right)$; and $\cos \theta_{s}$ is the solar zenith angle $[27,28]$.

(b) In the case of Landsat-8 OLI:

$$
\rho_{\lambda}=\frac{M_{\rho} * Q_{c a l}+A_{\rho}}{\sin \theta}
$$

where $\rho_{\lambda}$ is the TOA planetary reflectance; $M \rho$ is the reflectance multiplicative scaling factor for the band from the metadata; $A \rho$ is reflectance additive scaling factor for the band from the metadata; $Q_{c a l}$ is $\mathrm{L} 1$ pixel value in $\mathrm{DN}$; and $\sin \theta$ is the solar elevation angle (from the metadata, or calculated) $[27,28]$.

\subsection{Computation of LST}

Pre-processed Landsat datasets (Section 2.2) were used for the retrieval of LST. In the datasets, thermal bands contain at-satellite brightness temperature expressed in degrees, Kelvin. At-satellite brightness temperature was scaled by using land surface emissivity $[7,12,30,31]$. Firstly, it was derived from the land surface emissivity $(\varepsilon)$ value (Equation (1)) [32]:

$$
\varepsilon=\mathrm{m} \mathrm{P}_{\mathrm{v}}+\mathrm{n}
$$

where $\mathrm{m}$ is $\left(\varepsilon_{\mathrm{v}}-\varepsilon_{\mathrm{s}}\right)-\left(1-\varepsilon_{\mathrm{S}}\right) \mathrm{F} \varepsilon_{\mathrm{v}} ; \mathrm{n}$ is $\varepsilon_{\mathrm{S}}+\left(1-\varepsilon_{\mathrm{S}}\right) \mathrm{F} \varepsilon_{\mathrm{v}} ; \varepsilon_{\mathrm{S}}$ is the soil emissivity; $\varepsilon_{\mathrm{v}}$ is the vegetation emissivity; $F$ is a shape factor whose mean value, assuming different geometrical distributions, is 0.55 [32]. In this study, we adopted the result of [32] for $m$ as 0.004 and $n$ as $0.986 . P_{v}$ is the amount of vegetation computed by NDVI (Equation (9)). Subsequently, we calculated the proportion of vegetation (Equation (7)):

$$
\mathrm{P}_{\mathrm{V}}=\left(\left(\mathrm{NDVI}-\mathrm{NDVI}_{\min }\right) /\left(\mathrm{NDVI}_{\max }-\mathrm{NDVI}_{\min }\right)\right)^{2}
$$

where NDVI calculated by Equation (9) (Section 2.4.1), the NDVI $I_{\min }$ is minimum values of the NDVI, and $\mathrm{NDVI}_{\max }$ is the maximum value of the NDVI.

Finally, Equation (8) was calculated the emissivity-corrected LST [30]:

$$
\mathrm{LST}=\mathrm{T}_{\mathrm{b}} / 1+\left(\lambda \times \mathrm{T}_{\mathrm{b}} / \rho\right) \ln \varepsilon
$$

where $T_{b}$ is the at-satellite brightness temperature in degrees Kelvin; $\lambda$ is the central band wavelength of emitted radiance $(11.5 \mu \mathrm{m}$ for Band 6 [30] and $10.8 \mu \mathrm{m}$ for Band 10 [12]; $\rho$ is $\mathrm{h} \times \mathrm{c} / \sigma$ $\left(1.438 \times 10^{-2} \mathrm{~m} \mathrm{~K}\right)$ with $\sigma$ is the Boltzmann constant $\left(1.38 \times 10^{-23} \mathrm{~J} / \mathrm{K}\right), \mathrm{h}$ is Planck's constant $\left(6.626 \times 10^{-34} \mathrm{~J}\right.$ *s), and $\mathrm{c}$ is the velocity of light $\left(2.998 \times 10^{8} \mathrm{~m} / \mathrm{s}\right)$; and $\varepsilon$ is the land surface emissivity estimated using the NDVI method [32]. Finally, the calculated LST values (Kelvin) have been converted to $\left({ }^{\circ} \mathrm{C}\right)$.

Atmospheric data were not readily available to the authors, and the analyses are primarily confined to a single scene (within-year) analyses. Thus, the atmospheric corrections were neglected.

\subsection{Urban Surface Characteristics with LST}

Usages of spectral indices are the most common and applicable approach to compute the urban surface characteristic (USC) in large-scale research. Evidence of the past research indicates that the 
computation of USC by using spectral indices draws the precise and significant results $[13,33,34]$. All remote sensing indices were computed by using atmospherically-corrected reflectance.

\subsubsection{The Normalized Difference Vegetation Index (NDVI)}

NDVI has been widely used for the urban climate studies including for detecting vegetation coverage or GS. The substantial vegetation can make a cool island to mitigate the high temperature, while the lower vegetation area accelerates the level of temperature [35]. Hence, the usage of NDVI as one indicator for assessing the SUHI is most essential and previous research also gained a reliable result by following the same method [13,36]. The value of the NDVI is ranging between -1 to 1 . Its higher positive value denotes dense vegetation, and its low positive value represents bare soil or built-up areas, while its minors or its value closer to zero are linked to water [37-39]. The NDVI is calculated with Equation (9) as follows,

$$
\mathrm{NDVI}=\frac{\rho_{\text {NIR }}-\rho_{\text {Red }}}{\rho_{\text {NIR }}+\rho_{\text {Red }}}
$$

where $\rho_{\text {NIR }}$ refers to the surface reflectance values of Band 4 (Landsat-7), and Band 5 (Landsat-8); $\rho_{\text {Red }}$ refer to the surface reflectance values of Band 3 (Landsat-7), and Band 4 (Landsat-8 OLI).

\subsubsection{The Normalized Difference Built-Up Index (NDBI)}

NDBI is an indicator the built-up area of the Lagos City [12,40]. NDBI denotes the density of built-up in unit pixels, and its value ranging between -1 to 1 . Its positive value denotes built-up areas, and its negative numbers represents a surface water body, while a zero value usually belongs to vegetation $[12,40]$. The NDBI is shown as following (Equation (10)):

$$
\mathrm{NDBI}=\frac{\rho_{\text {SWIR } 1}-\rho_{\text {NIR }}}{\rho_{\text {SWIR } 1}+\rho_{\text {NIR }}}
$$

where $\rho_{\text {SWIR } 1}$ refers to the surface reflectance values of Band 5 (Landsat-7) and Band 6 (Landsat- 8 ); $\rho_{N I R}$ refers to the surface reflectance values of Band 4 (Landsat-7) and Band 5 (Landsat-8).

\subsubsection{Modified Normalized Difference Water Index (MNDWI)}

MNDWI is widely used as the spectral index for enhancing the water information effectively in most cases, and past research revealed that its use in SUHI studies had significant results $[7,12,41]$. The MNDWI is derived using the following (Equation (11)):

$$
\mathrm{MNDWI}=\frac{\rho_{\text {Green }}-\rho_{\text {SWIR } 1}}{\rho_{\text {Green }}+\rho_{\text {SWIR } 1}}
$$

where $\rho_{\text {Green }}$ refers to the surface reflectance values of Band 2 (Landsat-7) and Band 3 (Landsat-8); and $\rho_{\text {SWIR } 1}$ refer to the surface reflectance values of Band 5 (Landsat-7) and Band 6 (Landsat-8).

Afterward, Otsu's optimal thresholding method was applied [42] in order to distinct the water from other land use. Some previous research could be identified that has incorporated the same methodology $[7,12,26]$. Finally, all of the water bodies have been masked from all variables, such as NDVI, NDBI, population density (PD), fossil fuel, and $\mathrm{CO}_{2}$ emission (FFCOE) data in both period. 


\subsection{Socio-Economic Factors with LST}

\subsubsection{Population Density Data}

In Lagos State, approximately 600,000 people are added to the annual populations, and it generates various kinds of environmental issues not only in the city area but also in the periphery area. Expansion of built-up areas in order to provide settlement, industrial zones, and roads are some of the highlighted changes which are influenced by the high population density [16]. Some similar studies have adopted population density as a sociological variable in SUHI studies $[11,36]$. Due to the inaccessibility of PD ground level data in Logos City to cover the study period, RS data were facilitated.

LandScan, the global database shows the geographical distribution of populations all over the world. The spatial resolution of this data is about 30 arc-seconds (nearly $1 \mathrm{~km}$ ) [43]. It is available as an Environmental Systems Research Institute (ESRI) binary raster format which is computable to the analysis with Landsat data. Hence, this population data is more popular in demographic studies which are combining with Landsat [11,16]. For this analysis, $1 \mathrm{~km} \times 1 \mathrm{~km}$ mesh was created with same snapped with raster population map for 2002 and 2013 based on LandScan data. Then, the population density (PD) of each $1 \mathrm{~km} \times 1 \mathrm{~km}$ grid was calculated [11].

\subsubsection{Fossil-Fuel $\mathrm{CO}_{2}$ Emission Data}

International Energy Agency (IEA) survey in 2010 stated that $71 \%$ of global energy-related $\mathrm{CO}_{2}$ emissions were reported from an urban area with the increasing trend [16]. The Intergovernmental Panel on Climate Change (IPCC) model computed that $\mathrm{CO}_{2}$ content could be double in end of the 21st era and the mean temperature will increase from 1.5 to $2.5^{\circ} \mathrm{C}$, creating significant changes in ecosystem service around the cities [16]. Nearly 75\% of Nigeria's commercial activities are accumulated in the Lagos capital region [44]. Hence, there is a higher possibility to use fossil fuels in the industrial and transportation sectors. From this viewpoint, considering the fossil fuel, $\mathrm{CO}_{2}$, and its effects on the SUHI is essential.

The fossil-fuel $\mathrm{CO}_{2}$ emission dataset which provides by the Center for Global Environmental Research, National Institute for Environmental Studies as an open-data inventory for anthropogenic carbon dioxide (ODIAC) [45]. Moreover, high spatial resolution $\mathrm{CO}_{2}$ emissions from fossil fuel burning draw appropriate research results not only from an energy consumption point of view [46,47], but also from SUHI viewpoint [11]. In this study, fossil-fuel $\mathrm{CO}_{2}$ emission (FFCOE) data were derived by using $1 \mathrm{~km} \times 1 \mathrm{~km}$ grid for 2002 and 2013.

\subsection{Gradient Analysis}

The Gradient analysis applies to compute the spatial variation of environmental variables from city center to rural area, and it is one of the most commonly used methods in various kinds of research around the world [48,49]. This research was employed for the computation of the spatial pattern of the average LST, average NDVI, and average NDBI from the city midpoint to the peripheral along the gradient zone. First, the sequence of buffer zones was created around the city center with a $500 \mathrm{~m}$ distance interval. In this process, City hall (latitude $6^{\circ} 27.036^{\prime} \mathrm{N}$, longitude $3^{\circ} 23.850^{\prime} \mathrm{E}$ ) was considered as the central point of the buffer zones. We have created 100 buffer zones from the city midpoint to the periphery area $(500 \mathrm{~m} \times 100=50,000 \mathrm{~m}$ or $50 \mathrm{~km})$. Subsequently, the average values of the LST, NDVI, and NDBI were extracted by using a zonal statistic function. All of the water bodies, including inland and part of the sea (Atlantic Ocean), were excluded as explained in Section 2.4.3 [7,12].

\subsection{Statistical Analysis}

Statistical analysis was accomplished to compute the relationship with LST and USC and LST with socio-economic variables [33]. In this process, three procedures have been conducted: (i) the maps of LST, NDVI, and NDBI in two-time-point were downscaled into one kilometer by using a resampling technique, (ii) we created $1 \mathrm{~km} \times 1 \mathrm{~km}$ meshes excepting water bodies, and it consisted of 
4002 grids, and (iii) the values of each variable have been extracted from the mesh. The dependent variable values were extracted from LST, and the values of the NDVI, NDBI, PD, and FFCOE were acquired as the independent variable of each pixel, and these data were facilitated as the input of the statistical analysis [50]. Finally, scatter plots, and partial least square (PLS) regression analysis was employed to calculate the relationship between LST with other variables. PLS analysis is one of the methods most commonly utilized to assess the collinearity between one continuous dependent variable and two or more independent variables.

PLS regression has reported as useful technique for prediction in various areas of application, for instance: the strategic management area [51], the psychophysiological area [52], and the biology science [53]. The study by Farkas and Héberger (2005) [54] has revealed that the PLS algorithm is competitive with regularized regression methods, namely the (i) ridge regression and (ii) principal component regression, concerning the mean squared prediction error. Almøy (1996) found that the optimal number of PLS base components is frequently much lesser than that of principal component regression [55].

PLS is an approach to model relations among groups of observed predictors using latent variables, or when the predictors are highly collinear [56], while additional details regarding PLS methods can be identified in Schwartz (2009) [56] (Equations (12)-(14)). Let X $\subset$ Rm represent an m-dimensional space of feature vectors and, similarly, let $Y \subset R m$ be a one-dimensional space denoting the labels of class. Let the number of samples be $n$. PLS decomposes the zero-mean matrix $X(n \times m)$ and zero-mean vector $Y(\mathrm{n} \times 1)$ into:

$$
\begin{aligned}
& X=T P^{T}+E \\
& Y=U q^{T}+f
\end{aligned}
$$

where $T$ and $U$ are $\mathrm{n} \times \mathrm{p}$ matrices containing $\mathrm{p}$ extracted latent vectors, the $(\mathrm{m} \times \mathrm{p})$ matrix $\mathrm{P}$ and the $(1 \times \mathrm{p})$ vector $\mathrm{q}$ represent the loadings and the $\mathrm{n} \times \mathrm{m}$ matrix $E$ and the $\mathrm{n} \times 1$ vector $f$ are the residuals. The PLS method, using the nonlinear iterative partial least squares algorithm, constructs a set of weight vectors (or projection vectors) $W=\{w 1, w 2, \ldots, w p\}$ such that:

$$
\left[\operatorname{cov}\left(t_{i}, u_{i}\right)\right]^{2}=\left|w_{i}\right|^{\max }\left[\operatorname{cov}\left(X w_{i}, y\right)\right]^{2}
$$

where $t_{i}$ is the $i$-th column of matrix $T$, and $u_{i}$ the $i$-th column of matrix $U$, and $\operatorname{cover}\left(t_{i}, u_{i}\right)$ is the sample covariance between latent vectors $t_{i}$ and $u_{i}$. After the extraction of the latent vectors $t_{i}$ and $u_{i}$, the matrix $X$ and vector $y$ are deflated by subtracting their rank-one approximations based on $t_{i}$ and $u_{i}$. This process is repeated till the desired number of latent vectors had been extracted.

PLS version 2 was used to conduct PLS analysis using an algorithm with a missing value of -0.1 , weighting scheme of the path, maximum iteration number of 500, and stop criterion accuracy of 0.0010 . Bias-Corrected and Accelerated (BCa) Bootstrap was applied as a default since it is the most stable method that does not need excessive computing time [57].

\section{Results}

\subsection{Distribution of the LST}

The spatial distribution of the LST of the Lagos region in 2002 and 2013 are shown in Figure 2. On 12 December 2002 , the LST was ranged from $17.46^{\circ} \mathrm{C}$ to $40.18{ }^{\circ} \mathrm{C}$, with an average of $26.26^{\circ} \mathrm{C}$. On 18 December 2013 , it ranged from $23.49^{\circ} \mathrm{C}$ to $41.14{ }^{\circ} \mathrm{C}$, while the mean value reported was $28.57^{\circ} \mathrm{C}$. 
(a)

$12^{\text {th }}$ December 2002 - 09:51:17 GMT



(b)

$18^{\text {th }}$ December 2013 - 10:04:25 GMT
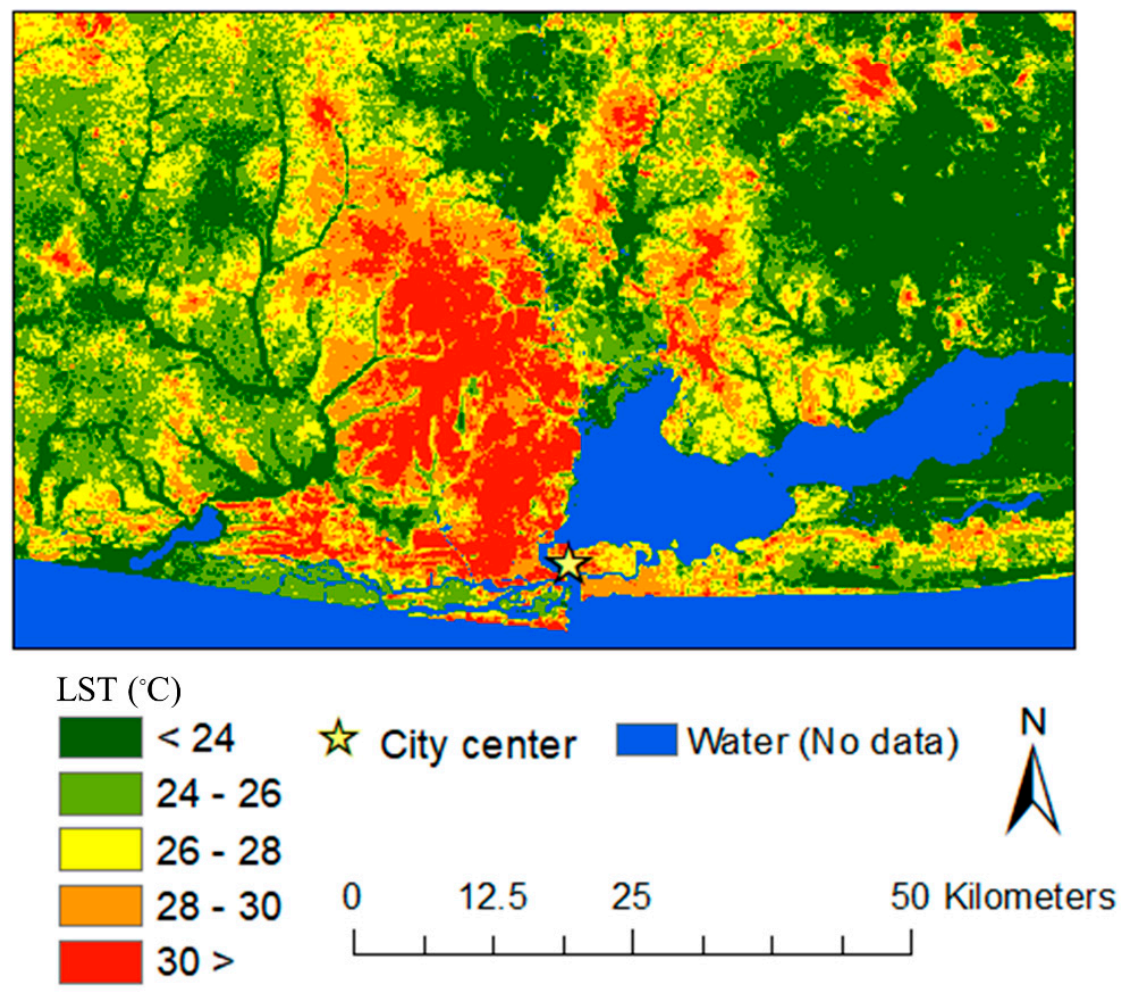

Figure 2. LST map of Lagos City; (a) 2002, and (b) 2013.

\subsection{Influence of Urban Surface Characteristic on LST}

Distribution and relationship of the LST with NDVI and NDBI were discussed as urban surface characteristics.

\subsubsection{LST with NDVI}

The NDVI map of Lagos City with scatter plots and simple linear regression analyses are illustrated in Figure 3. The value of the NDVI ranged between -0.30 and 0.45 in 2002, and it ranged between -0.06 and 0.39 in 2013. The areas with high NDVI values can be identified in the northeast and 
northwest portion of the study area in 2002 and 2013. Scatter plots, simple linear regression analyses were performed to assess the relationship with LST and NDVI. The strong negative correlation with LST and NDVI illustrates that high vegetation areas are most liable for controlling the SUHI effect and low NDVI areas are significant for the expansion of the SUHI effect [49].


Figure 3. NDVI map of Lagos City; (a) NDVI in 2002, (b) NDVI in 2013, (c) scatter plot diagram between LST and NDVI in 2002, and (d) scatter plot diagram between LST and NDVI in 2013.

\subsubsection{LST with NDBI}

The NDBI values ranged between 0.47 and 0.92 in 2002, and -0.06 to 0.86 in 2013 for the Lagos City areas as shown in Figure 4. Scientific literature shows that NDBI represents the built-up area and the spatial outline of city development [58]. The result of the NDBI illustrates that Lagos City has developed towards the northwest direction rather than the other areas. Geographical features might be the influence of this spatial variation of NDBI in 2002 and 2013. A large lagoon spreads close to the city midpoint in the eastern direction, and the southern portion of the city belongs to the coastal area. However, some part of the coastal area is occupied as an urban area where the harbor is located. The significant positive correlation between the LST and NDBI in both time points illustrates the influence of built-up areas for the expansion of high LST in Lagos City. 

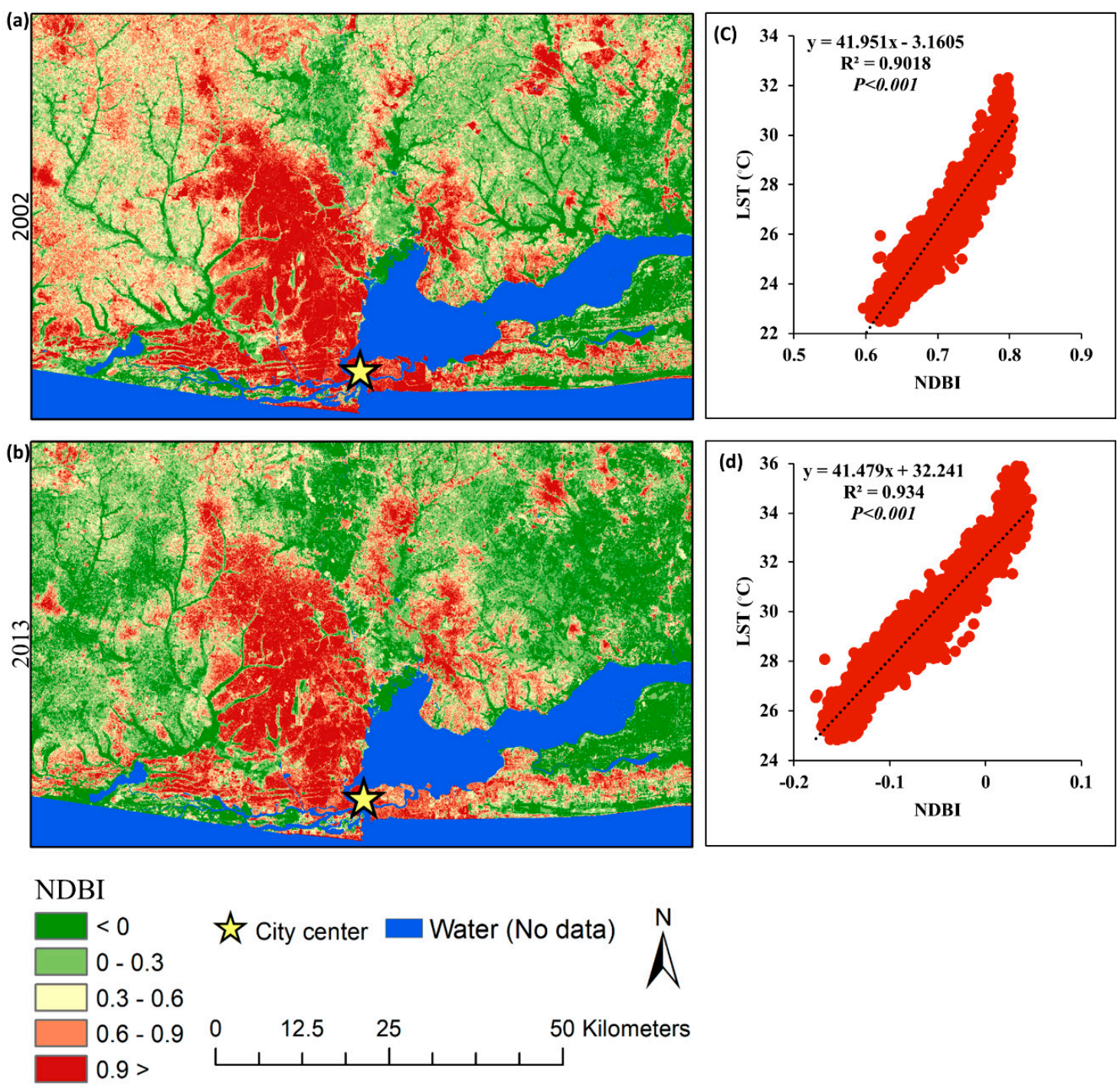

Figure 4. NDBI map of Lagos City; (a) NDBI in 2002, (b) NDBI in 2013, (c) scatter plot diagram between LST and NDBI in 2002, and (d) scatter plot diagram between LST and NDBI in 2013.

LST and NDBI were more closely related than the relationship between LST and NDVI, and it was found that the built-up area has a noticeable effect on the SUHI.

\subsection{Influence of Socio-Economic Factors for LST}

\subsubsection{Population Density with LST}

The population density (PD) of Lagos City is shown in Figure 5. Mean population density in 2002 and 2013 was 1572 per $\mathrm{km}^{2}$ and 2063 per km², respectively. It is observed that the areas where population density increased were mainly accumulated in the city center and suburban area in both periods. The distribution pattern is mainly focusing on the northwest direction as the same pattern shown in NDBI (Figure 4). The pattern indicates that rapid urbanization and economic development influence on the population density [16]. Moreover, the population distribution along the coastal zone had greater improvement in 2013. Population density is not strongly correlated with LST, but it has considerable improvement in 2013 compared to 2002. The LST and PD have been statistically significant $(p<0.001)$ in both time points. 

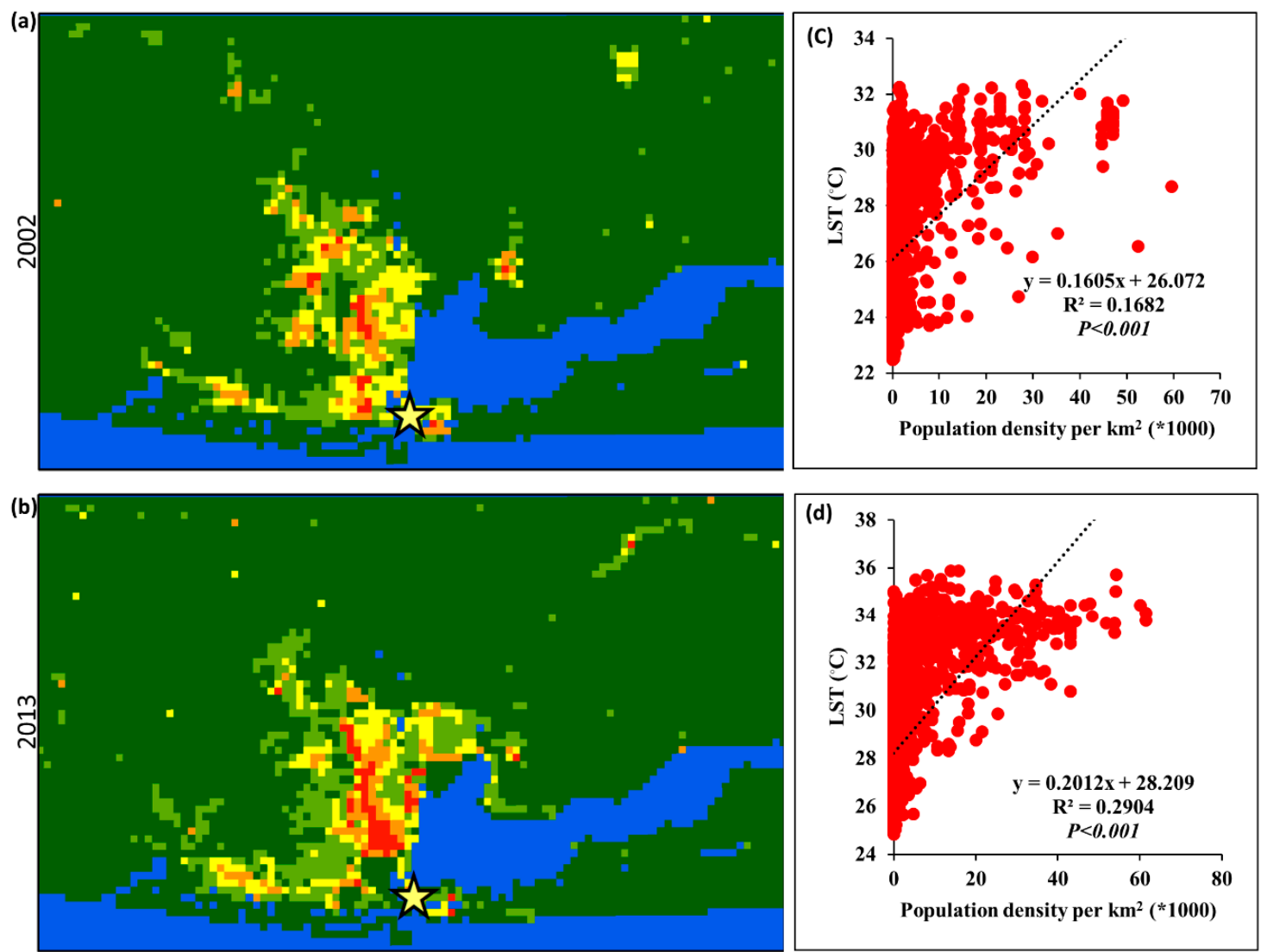

Population density per $\mathrm{km}^{2}\left({ }^{*} 1000\right)$
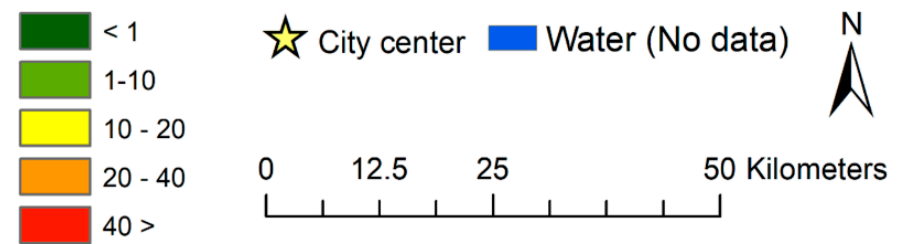

Figure 5. Population density (PD) map of Lagos City; (a) PD in 2002, (b) PD in 2013, (c) scatter plot diagram between LST and PD in 2002LST and PD in 2002, and (d) scatter plot diagram between LST and PD in LST and PD in 2013.

\subsubsection{Fossil Fuel $\mathrm{CO}_{2}$ Emission with LST}

The spatial and temporal distribution pattern of the FFCOE and the corresponding linear regression analysis are shown in Figure 6. In a temporal point of view, it is observed that mean FFCOE (tons of carbon cell per month) has been increased from 18.44 to 34.71 in between 2002 and 2013 , respectively. As a spatial point of view, the emission pattern of the $\mathrm{CO}_{2}$ has been spread towards the northwest direction from the city center showing the similar pattern of NDBI (Figure 4) in both time points. Further, significant positive relationship can be seen between urbanization and FFCOE. Though the value of the coefficient of determination was not high in both periods, the results were statistically significant $(p<0.001)$. 



Fossil fuel $\mathrm{CO}_{2}$ emissions (Tonnes of carbon cell per month)

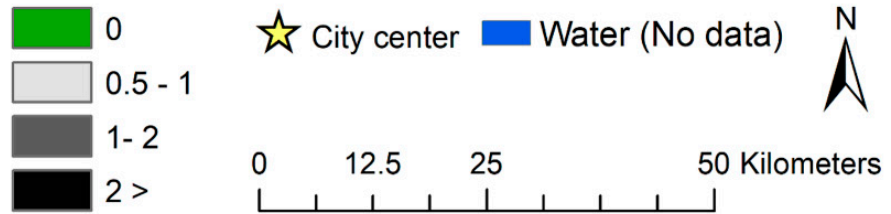

Figure 6. FFCOE map of Lagos City; (a) 2002, (b) 2013, (c) scatter plot diagram between of LST and FFCOE in 2002, and (d) scatter plot diagram between LST and FFCOE in 2013.

\subsection{Partial Least Square Regression}

PLS regression analysis has been performed for 2002 and 2013, and the influence of PD, FFCOE, NDVI, and NDBI for the variation of LST was calculated. Table 2 and Table 5 illustrated the correlation of LST with other variables in 2002 and 2013, respectively. The highest significant positive correlation between the LST and NDBI in both time points illustrates the influence of built-up for the increase of LST in Lagos City. LST has been negatively correlated NDVI in 2002 and 2013. Further, it is illustrated that the power of the green cover to reduce the effect of LST in the urban environment is important. Herein, we used the threshold value of correlation which was more than of 0.65 to set the latent variables, regarding some previous studies which recommended about 0.6 or $0.7[59,60]$.

Table 2. Correlation in LST 2002.

\begin{tabular}{cccccc}
\hline Variables & PD & FFCOE & NDVI & NDBI & LST \\
\hline PD & 1 & & & & \\
FFCOE & 0.55 & 1 & & & \\
NDVI & -0.496 & -0.732 & 1 & & \\
NDBI & 0.344 & 0.552 & -0.848 & 1 & \\
LST & 0.378 & 0.579 & -0.826 & 0.95 & 1 \\
\hline
\end{tabular}


For LST 2002, it revealed that NDVI had a high correlation with FFCOE of 0.732, indicating that the portion of NDVI as green space representation affected to FFCOE value. The larger the green space constructed, the more the FFCOE value will reduce. The high correlation was also shown by the correlation of NDBI and NDVI in the negative tendency of 0.848 . It presented that the portion of NDBI as a built-up representation influenced the NDVI value. The larger the built-up area is established, the more the green space will be recessive. Hence, FFCOE and NDVI were latent variables with high collinearity with another variable. This hypothesis was adopted in the path model of PLS for LST 2002. The path coefficients then resulted for all independent and dependent variables as presented in Table 3. Using a $95 \%$ confidence interval (CI), T-statistics value showed adequate number, denoting the significant correlation between LST and FCOE, NDBI, PD, between NDVI and NDBI, and also between FFCOE and NDVI. The $p$ value presented is less than 0.005 . Thus, the designed model was valid for all variables. However, the low significance was presented for the correlation of LST and NDVI due to a T-statistic of $1.006(<1.96)$.

Table 3. Path Coefficients in LST 2002.

\begin{tabular}{cccccc}
\hline Variables & $\begin{array}{c}\text { Original } \\
\text { Sample (O) }\end{array}$ & $\begin{array}{c}\text { Sample Mean } \\
\text { (M) }\end{array}$ & $\begin{array}{c}\text { Standard Deviation } \\
\text { (STDEV) }\end{array}$ & $\begin{array}{c}\text { T Statistics } \\
\text { (| O/STDEV I) }\end{array}$ & $p$ Values \\
\hline FFCOE -> LST & 0.067 & 0.067 & 0.009 & 7.456 & 0 \\
NDBI -> LST & 0.915 & 0.915 & 0.011 & 79.838 & 0 \\
NDBI -> NDVI & -0.848 & -0.848 & 0.004 & 229.303 & 0 \\
NDVI -> FFCOE & -0.731 & -0.730 & 0.014 & 52.726 & 0 \\
NDVI -> LST & 0.016 & 0.016 & 0.016 & 1.006 & 0.315 \\
PD -> LST & 0.034 & 0.034 & 0.007 & 4.660 & 0 \\
\hline
\end{tabular}

The R-squared adjusted value of LST and NDVI was considered high, being above the cutoff of 0.65 [61,62]. Nevertheless, the R-squared adjusted value of FFCOE (Table 4) presented a moderate level of 0.535 , meaning that about $53 \%$ of the variance in FFCOE was explained by the path model.

Table 4. R-squared adjusted of LST 2002.

\begin{tabular}{cccccc}
\hline Variables & $\begin{array}{c}\text { Original } \\
\text { Sample (O) }\end{array}$ & $\begin{array}{c}\text { Sample Mean } \\
\text { (M) }\end{array}$ & $\begin{array}{c}\text { Standard Deviation } \\
\text { (STDEV) }\end{array}$ & $\begin{array}{c}\text { T Statistics } \\
(\text { | O/STDEVI) }\end{array}$ & $p$ Values \\
\hline FFCOE & 0.535 & 0.536 & 0.019 & 28.287 & 0.000 \\
LST & 0.907 & 0.907 & 0.003 & 306.226 & 0.000 \\
NDVI & 0.72 & 0.72 & 0.006 & 124.027 & 0.000 \\
\hline
\end{tabular}

Therefore, the regression based on path coefficients value of the original sample (O) for LST 2002, as shown in Table 3, can be determined as follows (Equations (15)-(17)):

$$
\begin{gathered}
L S T=0.067 F F C O E+0.915 N D B I+0.016 N D V I+0.034 P D \\
N D V I=-0.848 N D B I \\
F F C O E=-0.731 \mathrm{NDVI}
\end{gathered}
$$

For LST 2013, the collinearity of predictors was predicted using the same threshold of LST 2002. Regarding the correlation value, the latent variables were assumed for FFCOE, which had a high correlation with NDBI, NDVI, and PD (Table 5). For NDBI and PD, the positive tendency was showed for those correlations. Herein, the larger the NDBI value as the built-up representation and the larger the PD as population density, the higher the FFCOE value. Similar to LST 2002, the NDVI variable also had collinearity with NDBI in a negative trend. Using this hypothesis, the path model was then produced with the path coefficient, as presented in Table 6 . Concerning the T-statistics, it revealed that all variables had a value of more than 1.96 (95\% CI). The $p$ value for all variables showed an acceptance level which was less than 0.05 , indicating that the designed models were valid for all variables. 
Table 5. Correlation in LST 2013.

\begin{tabular}{cccccc}
\hline Variables & PD & FFCOE & NDVI & NDBI & LST \\
\hline PD & 1 & & & & \\
FFCOE & 0.658 & 1 & & & \\
NDVI & -0.544 & -0.771 & 1 & & \\
NDBI & 0.474 & 0.688 & -0.934 & 1 & 1 \\
LST & 0.518 & 0.719 & -0.897 & 0.966 & 1 \\
\hline
\end{tabular}

Table 6. Path coefficients LST 2013.

\begin{tabular}{cccccc}
\hline Variables & $\begin{array}{c}\text { Original } \\
\text { Sample (O) }\end{array}$ & $\begin{array}{c}\text { Sample Mean } \\
\text { (M) }\end{array}$ & $\begin{array}{c}\text { Standard Deviation } \\
\text { (STDEV) }\end{array}$ & $\begin{array}{c}\text { T Statistics } \\
\text { (|O/STDEVI) }\end{array}$ & $p$ Values \\
\hline FFCOE -> LST & 0.119 & 0.119 & 0.01 & 12.248 & 0 \\
NDBI -> FFCOE & -0.162 & -0.163 & 0.025 & 6.416 & 0 \\
NDBI -> LST & 1.052 & 1.052 & 0.013 & 79.032 & 0 \\
NDBI -> NDVI & -0.934 & -0.934 & 0.002 & 516.194 & 0 \\
NDVI -> FFCOE & -0.742 & -0.742 & 0.031 & 23.717 & 0 \\
NDVI -> LST & 0.206 & 0.207 & 0.017 & 12.19 & 0 \\
PD -> FFCOE & 0.332 & 0.332 & 0.019 & 17.728 & 0 \\
PD -> LST & 0.053 & 0.054 & 0.006 & 8.536 & 0 \\
\hline
\end{tabular}

For the R-squared adjusted value, it showed that the path model was significant in the value of more than 0.65 , indicating that those values had a significant dependence on those valid path models. The R-squared adjusted value of FFCOE, NDVI, and LST (Table 7) appeared to increase compared to that of LST 2002.

Table 7. R-squared adjusted of LST 2013.

\begin{tabular}{cccccc}
\hline Variables & $\begin{array}{c}\text { Original } \\
\text { Sample (O) }\end{array}$ & $\begin{array}{c}\text { Sample Mean } \\
\text { (M) }\end{array}$ & $\begin{array}{c}\text { Standard Deviation } \\
\text { (STDEV) }\end{array}$ & $\begin{array}{c}\text { T Statistics } \\
\text { (| O/STDEVI) }\end{array}$ & $p$ Values \\
\hline FFCOE & 0.678 & 0.678 & 0.018 & 38.049 & 0.000 \\
LST & 0.945 & 0.945 & 0.002 & 569.12 & 0.000 \\
NDVI & 0.873 & 0.872 & 0.003 & 258.14 & 0.000 \\
\hline
\end{tabular}

Therefore, the regression based on the value of the original sample (O) for LST 2013, as shown in Table 6, can be determined as follows, (Equations (18)-(20)):

$$
\begin{gathered}
L S T=0.1197 F F C O E+1.052 N D B I+0.206 N D V I+0.0534 P D \\
N D V I=-0.934 N D B I \\
F F C O E=0.332 P D-0.742 N D V I-0.162 N D B I
\end{gathered}
$$

The R-squared for FFCOE, LST, and NDVI was greater than 0.5 compared to the 2002. 


\section{Discussion}

\subsection{Urbanization and Urban Expansion in Lagos City}

Lagos City was developed as a port city from the colonial period, and it was developed after the petroleum booming between 1970 and 1980 [16,17]. Rural-urban migration had been influenced to increase the number of population in Lagos City in the past half of the century, and the urbanization rate had spiraled out of control [16]. The result of the urban-rural gradient analysis (Figure 7) illustrates the variation of the mean value of LST, NDVI, and NDBI from the city midpoint to the rural area. The mean NDBI represents the man-made environment or built-up areas and means that NDVI is representing the natural vegetation cover or GS in Figure 7a,d, correspondently. The similar pattern can be identified throughout the mean NDBI and mean LST along the urban rural gradient. Excepting the small fluctuation, both are gradually declining from the city center to rural areas along the urban-rural gradient in 2002 and 2013. The pattern of the urban expansion can be observed through the variation of mean NDBI, and the comparatively mean NDBI in 2013 is higher than the mean NDBI in 2002. The LST strong positive correlation with NDBI indicates that urbanized areas directly influence LST and the formation of the SUHI. As discussed above, adding 600,000 people per year into the urban population may influence this scenario in Lagos City. It could be predicted that LST will increase both spatially and temporally more than the present level. The lack of vegetated areas is remarkably highlighted surrounding the city area, compared to the rural area in both time points, as shown in Figure $7 \mathrm{~d}$, and this could transform green surfaces into built-up areas due to the land demand for the expanding of social needs. However, the green area can influence a reduction in the magnitude of the LST, and its solution for controlling of SUHI; LST and NDVI are negatively correlated, and both are statistically significant $(p<0.001)$. Moreover, the green surface is gradually increased from the city midpoint to the country side expecting the small fluctuation along the gradient zones. The scientific literature [37] reveals that lower LSTs can be frequently found in the area where NDVI is high, and upper LSTs customarily represent the opposite of this scenario; this could be clearly examined in Lagos City through the urban-rural gradient analysis. Fast expansion of Lagos City has led to significant and irreversible deviations in the land use pattern and its characteristics with the increase of SUHI [5].

Robin Bloch [17] stated that the decentralization of population and economic activities in the low-density metropolitan areas is a new trend in Nigeria's urbanization process [17]. As a general overview, the result of the urban-rural gradient analysis also shows this pattern. Though there is a small fluctuation of increasing pattern of built-up from 2002 to 2013 through the gradient analysis, the accountable changing pattern can be observed beyond $28 \mathrm{~km}$ from the city center, and vast urban expansion had taken place in the suburban area rather than the city center as shown as "the major urban expansion area" (Figure 7a). 


\section{NDBI}

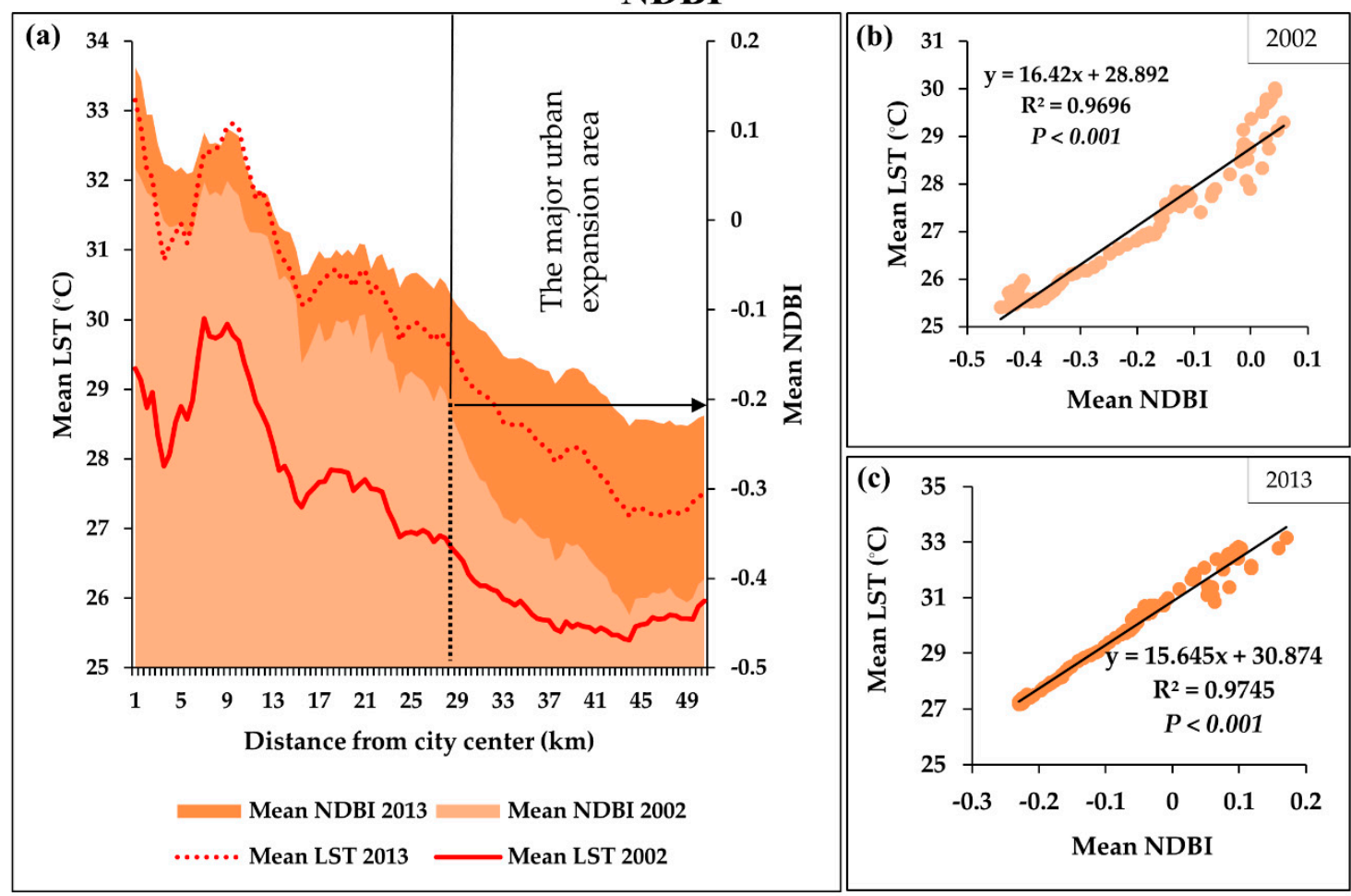

\section{NDVI}

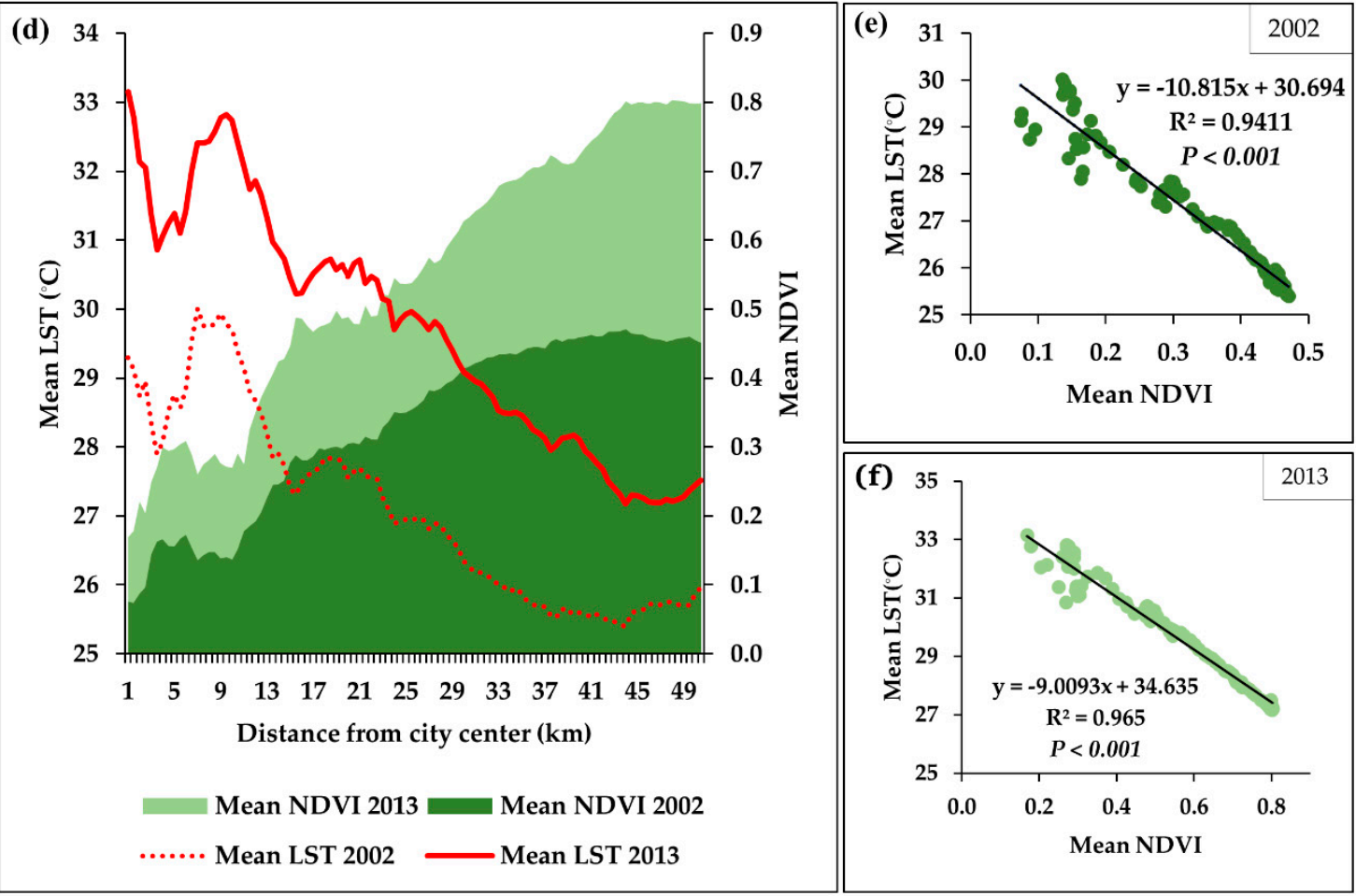

Figure 7. The spatial outline of the LST, NDVI, and NDBI with gradient: $(\mathbf{a}, \mathbf{d})$ spatial pattern of the mean LST with NDBI and NDVI in 2002 and 2013, (b,c) scatter plots and statistical relationship among mean LST with average NDBI in 2002 and 2013, and (e,f) scatter plots and statistical relationship among average LST with average NDVI in 2002 and 2013. 


\subsection{USC and Socio-Economic Factors with LST}

Expanding of socio-economic activities on the urban area is directly influenced by the increase of the gross domestic product (GDP), which has been widely used to evaluate the development pattern and its trends [7,17]. The GDP of Nigeria was 5911.7 billion US\$ in 2002, and it was 51,496.6 billion US\$ in 2013 [63]. Remarkably, it can be observed that GDP has dramatically increased during the study period. The Lagos metropolis makes the most significant influence on Nigeria's leading economic development. In 2006, Lagos contribution was 30\% of Nigeria's GDP, including 90\% of its overseas trade and $70 \%$ of its business investments [16]. However, the expanding of socio-economic activities is a driving force of the SUHI on the intensive urban structure, which consists of high population density, energy demand, and air pollution [13].

In 2010, the population of Lagos City was 10.78 million, and it was predicted to be 16.17 million in 2020, while the average growth rate was reported as 4.45 million in a decade [17]. The high populated urban structure is usually accountably generating anthropogenic heat. However, the number of population or its growth rate is not directly influenced by SUHI, but it causes for urbanization in order to enhance SUHI and its intensity [64], as demonstrated by Figure 4. Moreover, the significant positive correlations between LST and PD illustrated that there is a possibility to expose urban residences to heat-related health issues, e.g., heat stress.

Fossil fuels play a broader role in industrial, transportation, electricity generation, and domestic sectors. As we discussed above, when it increased GDP, there is a higher possibility of using more fossil fuels by the industrial sector. Additionally, the transportation sector of Lagos City had obtained greater improvement after the establishment of the municipal transport service in 1958 [16]. However, burning of fossil fuels causes the emission of $\mathrm{CO}_{2}$ and abnormal environmental changes, including increasing temperature [18,65]. A significant positive correlation of LST with FFCOE (Figure 6) illustrated the influence of fossil fuel $\mathrm{CO}_{2}$ on SUHI. The effect of LST is higher in the area where $\mathrm{CO}_{2}$ was highly accumulated in Lagos City between 2002 and 2013 (Figure 6). Moreover, the spatial distribution of the $\mathrm{CO}_{2}$ emission is shown in some similar pattern which is shown by NDBI (Figure 4); both are distributed along the northwest direction from the city center. By this pattern, we realize that urban expansion directly contributes to the emission of $\mathrm{CO}_{2}$ through the anthropogenic activities in Lagos City.

Based on the PLS of two periods, it revealed that NDVI had collinearity with NDBI, and FFCOE had multi-collinearity with NDVI. However, for 2013, FFCOE was also affected by PD and NDBI. It was in line with the study by Chen (2015) that urban green space (presented by NDVI) can mitigate the effect of FFCOE because plants function as carbon sinks through the biotic sequestration process [66]. In addition to that FFCOE is comparatively low in rural areas (Figure 6), but green space is high, as shown in Figure 7d. This might be the reason for the negative correlation between FFCOE and NDVI in 2002 and 2013. The urban areas (represented by NDBI) were much attributable in a steadily increasing FFCOE (Figure 6) due to the urban activities [67]. This could be the reason for showing the positive correlation between FFCOE and NDBI in both time points.

Even though FFCOE showed a positive correlation with LST (Tables 2, 3 and 6), nevertheless, there might be some hidden factors, such as cloud cover [68] or changes in transmittance and evaporation of land covers, which were related on some levels [69].

\subsection{The Implication for Sustainable Urban Planning in Lagos City}

Indeed, the outcomes of this research designate that urbanization of the Lagos metropolises had changed in both directions spatially and temporally during the study period and it is predicted to continue in the future because of its capital of Nigeria and its feeding 30\% of Nigeria's GDP. It pays a significant role in the world economic sector as an oil exporting country [1]. As a megacity, it dominates the seventh place in the world urbanization list [1]. Hence, an environmentally sound, socially acceptable, and economically viable urban planning system is indispensable for the sustainability of Lagos City. As a general aspect, urbanization brings socio-economic benefit to the community, 
including employment opportunities and infrastructure facilities for urban life, but it creates negative externalities to the natural environment $[11,36]$.

Results of the research reveal that the formation of SUHI is the result of changes in USC and the influence of the socio-economic activities. High thermal inertia is caused by showing the strong positive correlation between LST and NDBI (Figure 4). The area consisting of a green surface generally decreases the LST (Figure 3) because of lower thermal inertia and transpiration. Hence, it creates the cool island against the SUHI [12,58,59]. In this viewpoint, city planners of Lagos City should consider the urban green concept to preserve the current green areas, and future urban development should be focused to "goal 11", which is declared by the 2030 agenda for sustainable development $[70,71]$. However, urbanization and urban expansion are needed to upgrade the development stage of any country, and new construction should be encouraged with green approaches. Green walls are a concept that is applicable for both low- and high-rise buildings and an alternative to increasing the green zones in the city area [72]. The past study has evidenced that green walls can mitigate house inside temperatures in the tropical country by $2.4{ }^{\circ} \mathrm{C}[22,23]$. In Lagos as a tropical coastal city, this method will be applicable. In addition to this, green belts along the main roads and residential areas to motivate the cool island will be a solution for heat stress and a decrease of the demand for energy for ACs.

Increasing population and its density in the urban area are specific attributes but should be managed sustainably. The urban community should encourage the home garden and the green walls concept, examined above, in Lagos City. Consumption of renewable energy (solar power, wind power) will be an alternative solution for fossil fuels and mitigating the magnitude of $\mathrm{CO}_{2}$; transportation systems should be systematic to emit the minimum amount of $\mathrm{CO}_{2}$. Paying greater attention to the suburban area in Lagos City will be more advantageous to future planning because there is a higher possibility to expand the urban area into this region, as illustrated by the urban-rural gradient analysis (Figure 7).

\section{Conclusions}

This study was observed the spatial pattern of the LST by using urban surface characteristics and socio-economic variables in Lagos City, Nigeria between 2002 and 2013 based on remote sensing and geospatial approaches. USC has influenced the distribution pattern of the SUHI over the study period. The significant positive correlation between LST and NDBI illustrated that the expansion of built-up has directly contributed to the formation of SUHI, while the significant negative correlation between LST and NDVI has shown the SUHI mitigation power of the green surface in both time points. Socio-economic events have directly and indirectly influenced the formation of the SUHI liable urban environment in Lagos City. With the high growth rate of the population density, industrial activities, and demand for energy there is a possibility to transform suburban areas into urban areas and to reduce green space in the future as an outcome of urbanization. Hence, the authors expected that policymakers and city planners would consider this information for future activities. The authors would like to conclude that the overall outcomes of this research will able to use as a proxy indicator of future planning of Lagos City.

Author Contributions: The corresponding author, D.D., has proposed the topic and spearheaded the data processing and analysis, as well as the writing of the manuscript. T.M., Y.M., M.R., and H.H.H. helped in the design, research implementation and analysis, and writing of the manuscript.

Funding: This study was supported by the Japan Society for the Promotion of Science (JSPS) through Grant-in-Aid for Challenging Exploratory Research 16K12816 and Scientific Research (B) 18H00763.

Acknowledgments: The authors express their gratefulness to the anonymous reviewers for their valuable comments and suggestions.

Conflicts of Interest: The authors declare no conflict of interest. 


\section{References}

1. United Nations Development Programme (UNDP). Sustainable Urbanization Strategy-UNDP's Support to Sustainable, Inclusive and Resilient Cities in the Developing World; UNDP: New York, NY, USA, 2016.

2. United Nations (UN). World Urbanization Prospects: The 2014 Revision: Highlights; United Nations: New York, NY, USA, 2015; Volume 12.

3. Estoque, R.C.; Murayama, Y. Measuring sustainability based upon various perspectives: A case study of a hill station in Southeast Asia. Ambio 2014, 43, 943-956. [CrossRef] [PubMed]

4. Estoque, R.C.; Murayama, Y. Quantifying landscape pattern and ecosystem service value changes in four rapidly urbanizing hill stations of Southeast Asia. Landsc. Ecol. 2016, 31, 1481-1507. [CrossRef]

5. Ojeh, V.; Balogun, A.; Okhimamhe, A. Urban-rural temperature differences in Lagos. Climate 2016, 4, 29. [CrossRef]

6. Giridharan, R.; Emmanuel, R. The impact of urban compactness, comfort strategies and energy consumption on tropical urban heat island intensity: A review. Sustain. Cities Soc. 2018, 40, 677-687. [CrossRef]

7. Ranagalage, M.; Estoque, R.C.; Murayama, Y. An urban heat island study of the Colombo Metropolitan Area, Sri Lanka, based on Landsat Data (1997-2017). ISPRS Int. J. Geo-Inf. 2017, 6, 189. [CrossRef]

8. Igun, E. Analysis and sustainable management of urban growth's impact on land surface temperature in Lagos, Nigeria. J. Remote Sens. GIS 2017, 6. [CrossRef]

9. EPA (US Environmental Protection Agency). Reducing Urban Heat Islands: Compendium of Strategies Urban Heat Island Basics; US Environmental Protection Agency: Washington, DC, USA, 2008.

10. Howard, L. The Climate of London; W. Phillips: London, UK, 2018; Volume 1.

11. Zhang, X.; Estoque, R.C.; Murayama, Y. An urban heat island study in Nanchang City, China based on land surface temperature and social-ecological variables. Sustain. Cities Soc. 2017, 32, 557-568. [CrossRef]

12. Estoque, R.C.; Murayama, Y.; Myint, S.W. Effects of landscape composition and pattern on land surface temperature: An urban heat island study in the megacities of Southeast Asia. Sci. Total Environ. 2017, 577, 349-359. [CrossRef]

13. Min, M.; Zhao, H.; Miao, C. Spatio-temporal evolution analysis of the urban heat island: A case study of Zhengzhou City, China. Sustainability 2018, 10, 1992. [CrossRef]

14. Wang, H.; Zhang, Y.; Tsou, J.; Li, Y. Surface urban heat island analysis of Shanghai (China) based on the change of land use and land cover. Sustainability 2017, 9, 1538. [CrossRef]

15. Zhang, Y.; Odeh, I.O.A.; Han, C. Bi-temporal characterization of land surface temperature in relation to impervious surface area, NDVI and NDBI, using a sub-pixel image analysis. Int. J. Appl. Earth Obs. Geoinf. 2009, 11, 256-264. [CrossRef]

16. Filani, M.O. The Changing Face of Lagos: From Vision to Reform and Transformation; Lagos State Ministry of Physical Planning and Urban Development: Lagos, Nigeria, 2012; pp. 8-11.

17. Fox, S.; Bloch, R.; Ojo, A.; Monroy, J. Urbanisation and Urban Expansion in Nigeria; Urbanization Research Nigeria (URN) Research Report; Creative Commons Attribution-non-Commercial-Share Alike CC BY-NC-SA; ICF International: London, UK, 2015.

18. Aderogba, K.A. Greenhouse gas emissions and sustainability in Lagos Metropolis, Nigeria. Int. J. Learn. Dev. 2011, 1, 46-61. [CrossRef]

19. The World Bank. Population (Total) and Electric Power Consumption (kWh Per Capita). Available online: https: / / data.worldbank.Org/indicator/NY.GDP.MKTP.CD?locations=NG (accessed on 11 July 2018).

20. Babalola, O.S.; Akinsanola, A.A. Change detection in land surface temperature and land use a land cover over Lagos Metropolis, Nigeria. J. Remote Sens. GIS 2016, 5, 1-7.

21. Ayeni, A.O. Increasing population, urbanization and climatic factors in Lagos State, Nigeria: The nexus and implications on water demand and supply. J. Glob. Initiat. Policy Pedagog. Perspect. 2017, 11, 6.

22. Image Free Printing Source. Available online: https:// www.pinterest.com (accessed on 15 July 2018).

23. Guardian News Website in Nigeria, Africa. Available online: https:/ / guardian.ng (accessed on 15 July 2018).

24. United States Geological Survey (USGS) Website. Available online: https:/ / earthexplorer.usgs.gov (accessed on 20 June 2018).

25. Li, Z.L.; Tang, B.H.; Wu, H.; Ren, H.; Yan, G.; Wan, Z.; Trigo, I.F.; Sobrino, J.A. Satellite-derived land surface temperature: Current status and perspectives. Remote Sens. Environ. 2013, 131, 14-37. [CrossRef] 
26. Li, W.; Du, Z.; Ling, F.; Zhou, D.; Wang, H.; Gui, Y.; Sun, B.; Zhang, X. A comparison of land surface water mapping using the normalized difference water index from TM, ETM+ and ALI. Remote Sens. 2013, 5, 5530-5549. [CrossRef]

27. NASA. Landsat 7 Science Data Users Handbook. 11 March 2011. Available online: https:/ /landsat.gsfc.nasa. gov /landsat-7-science-data-users-handbook/ (accessed on 30 October 2018).

28. NASA. Landsat 8 Science Data Users Handbook. June 2015. Available online: https:/ /landsat.usgs.gov/ sites/default/files/documents/Landsat8DataUsersHandbook.pdf (accessed on 30 October 2018).

29. Adeyeri, O.E.; Akinsanola, A.A.; Ishola, K.A. Investigating surface urban heat island characteristics over Abuja, Nigeria: Relationship between land surface temperature and multiple vegetation indices. Remote Sens. Appl. Soc. Environ. 2017, 7, 57-68. [CrossRef]

30. Weng, Q.; Lu, D.; Schubring, J. Estimation of land surface temperature-vegetation abundance relationship for urban heat island studies. Remote Sens. Environ. 2004, 89, 467-483. [CrossRef]

31. Estoque, R.C.; Murayama, Y. Monitoring surface urban heat island formation in a tropical mountain city using Landsat data (1987-2015). ISPRS J. Photogramm. Remote Sens. 2017, 133, 18-29. [CrossRef]

32. Sobrino, J.A.; Jiménez-Muñoz, J.C.; Paolini, L. Land surface temperature retrieval from LANDSAT TM 5. Remote Sens. Environ. 2004, 90, 434-440. [CrossRef]

33. Chen, X.; Zhang, Y. Impacts of urban surface characteristics on spatiotemporal pattern of land surface temperature in Kunming of China. Sustain. Cities Soc. 2017, 32, 87-99. [CrossRef]

34. Handayani, H.H.; Murayama, Y.; Ranagalage, M.; Liu, F.; Dissanayake, D. Geospatial analysis of horizontal and vertical urban expansion using multi-spatial resolution data: A case study of Surabaya, Indonesia. Remote Sens. 2018, 10, 1599. [CrossRef]

35. Rani, M.; Kumar, P.; Pandey, P.C.; Srivastava, P.K.; Chaudhary, B.S.; Tomar, V.; Mandal, V.P. Multi-temporal NDVI and surface temperature analysis for Urban Heat Island inbuilt surrounding of sub-humid region: A case study of two geographical regions. Remote Sens. Appl. Soc. Environ. 2018, 10, 163-172. [CrossRef]

36. Ranagalage, M.; Estoque, R.C.; Zhang, X.; Murayama, Y. Spatial changes of urban heat island formation in the Colombo District, Sri Lanka: Implications for sustainability planning. Sustainability 2018, 10, 1367. [CrossRef]

37. Barbieri, T.; Despini, F.; Teggi, S. A multi-temporal analyses of Land Surface Temperature using Landsat-8 data and open source software: The case study of Modena, Italy. Sustainability 2018, 10, 1678. [CrossRef]

38. Wijesundara, N.C.; Abeysingha, N.S.; Dissanayake, D.M. GIS-based soil loss estimation using RUSLE model: A case of Kirindi Oya river basin, Sri Lanka. Model. Earth Syst. Environ. 2018, 4, 251-262. [CrossRef]

39. Dissanayake, D.; Morimoto, T.; Ranagalage, M. Accessing the soil erosion rate based on RUSLE model for sustainable land use management: A case study of the Kotmale watershed, Sri Lanka. Model. Earth Syst. Environ. 2018, 5, 1-16. [CrossRef]

40. Simwanda, M.; Murayama, Y. Spatiotemporal patterns of urban land use change in the rapidly growing city of Lusaka, Zambia: Implications for sustainable urban development. Sustain. Cities Soc. 2018, 39, 262-274. [CrossRef]

41. Son, N.T.; Chen, C.F.; Chen, C.R.; Thanh, B.X.; Vuong, T.H. Assessment of urbanization and urban heat islands in Ho Chi Minh City, Vietnam using Landsat data. Sustain. Cities Soc. 2017, 30, 150-161. [CrossRef]

42. Otsu, N. A threshold selection method from gray-level histograms. IEEE Trans. Syst. Man Cybern. 1979, 9, 62-66. [CrossRef]

43. LandScan Global Population Distribution Data. Available online: https://landscan.ornl.gov (accessed on 20 June 2018).

44. Hopkins, J.R.; Evans, M.J.; Lee, J.D.; Lewis, A.C.; Marsham, J.H.; McQuaid, J.B.; Parker, D.J.; Stewart, D.J.; Reeves, C.E.; Purvis, R.M. Direct estimates of emissions from the megacity of Lagos. Atmos. Chem. Phys. 2009, 9, 8471-8477. [CrossRef]

45. Center for Global Environmental Research, National Institute for Environmental Studies as an Open-Data Inventory for Anthropogenic Carbon Dioxide (ODIAC). Available online: http:/ / db.cger.nies.go.jp/dataset/ ODIAC/emission_dataset.html (accessed on 25 June 2018).

46. Oda, T.; Maksyutov, S. A very high-resolution $(1 \mathrm{~km} \times 1 \mathrm{~km})$ global fossil fuel $\mathrm{CO}_{2}$ emission inventory derived using a point source database and satellite observations of nighttime lights. Atmos. Chem. Phys. 2011, 11, 543-556. [CrossRef] 
47. Oda, T.; Maksyutov, S.; Andres, R.J. The Open-source Data Inventory for Anthropogenic $\mathrm{CO}_{2}$, version 2016 (ODIAC2016): A global monthly fossil fuel $\mathrm{CO}_{2}$ gridded emissions data product for tracer transport simulations and surface flux inversions. Earth Syst. Sci. Data 2018, 10, 87-107. [CrossRef]

48. Gunaalan, K.; Ranagalage, M.; Gunarathna, M.; Kumari, M.; Vithanage, M.; Srivaratharasan, T.; Saravanan, S.; Warnasuriya, T.W.S. Application of geospatial techniques for groundwater quality and availability assessment: A case study in Jaffna Peninsula, Sri Lanka. ISPRS Int. J. Geo-Inf. 2018, 7, 20. [CrossRef]

49. Rousta, I.; Sarif, M.O.; Gupta, R.D.; Olafsson, H.; Ranagalage, M.; Murayama, Y.; Zhang, H.; Mushore, T.D. Spatiotemporal analysis of land use/land cover and its effects on surface urban heat island using Landsat data: A case study of Metropolitan City Tehran (1988-2018). Sustainability 2018, 10, 4433. [CrossRef]

50. Xiao, H.; Kopecká, M.; Guo, S.; Guan, Y.; Cai, D.; Zhang, C.; Zhang, X.; Yao, W. Responses of urban land surface temperature on land cover: A comparative study of Vienna and Madrid. Sustainability 2018, 10, 260. [CrossRef]

51. Holland, J. Use of partial least squares (PLS) in strategic management research: A review of four recent studies. Comput. Stat. Data Anal. 1999, 20, 195-204. [CrossRef]

52. Lobaugh, N.J.; West, R.; McIntosh, A.R. Spatiotemporal analysis of experimental differences in event-related potential data with partial least squares. Psychophysiology 2001, 38, 517-530. [CrossRef]

53. Nguyen, D.; Rocke, D. Tumor classification by partial least squares using microarray gene expression data. Bioinformatics 2002, 18, 39-50. [CrossRef]

54. Farkas, O.; Héberger, K. Comparison of ridge regression, partial least-squares, pairwise correlation, forwardand best subset selection methods for prediction of retention indices for aliphatic alcohols. J. Chem. Inf. Model. 2005, 45, 339-346. [CrossRef]

55. Helland, I.S.; Almøy, T. Comparison of prediction methods when only a few components are relevant. J. Am. Stat. Assoc. 1994, 89, 583-591. [CrossRef]

56. Schwartz, W. Human detection using partial least squares analysis. In Proceedings of the 2009 IEEE 12 th International Conference on Computer Vision, Kyoto, Japan, 29 September-2 October 2009; pp. 24-31.

57. Ringle; Christian, M.; Wende; Sven; Will; Alexander. SmartPLS 2.0.M3; SmartPLS: Hamburg, Germany, 2005; Available online: http:/ / www.smartpls.com (accessed on 01 December 2018).

58. Ranagalage, M.; Estoque, R.C.; Handayani, H.H.; Morimoto, T.; Tadono, T.; Murayama, Y. Relation between urban volume and land surface temperature: A comparative study of planned and traditional cities in Japan. Sustainabilaity 2018, 10, 2366. [CrossRef]

59. Drezner, Z. Multirelation-A correlation among more than two variables. Comput. Stat. Data Anal. 1995, 19, 283-292. [CrossRef]

60. Vul, E.; Harris, C.; Winkielman, P.; Pashler, H. Puzzlingly High Correlations in fMRI Studies of Emotion, Personality, and Social Cognition. Perspect. Psychol. Sci. 2009, 4, 274-290. [CrossRef] [PubMed]

61. Hock, M.; Ringle, C.M. Local strategic networks in the software industry: An empirical analysis of the value continuum. Int. J. Knowl. Manag. Stud. 2010, 4, 132. [CrossRef]

62. O'Brien, T.A.; Kashinath, K.; Cavanaugh, N.R.; Collins, W.D.; O'Brien, J.P. A fast and objective multidimensional kernel density estimation method: FastKDE. Comput. Stat. Data Anal. 2016, 101, 148-160. [CrossRef]

63. The World Bank, World Development Indicators: GDP (Currency US\$). Available online: https:// data. worldbank.org/indicator/NY.GDP.MKTP.CD?locations=NG (accessed on 17 July 2018).

64. Bokaie, M.; Zarkesh, M.K.; Arasteh, P.D.; Hosseini, A. Assessment of urban heat island based on the relationship between land surface temperature and land use/land cover in Tehran. Sustain. Cities Soc. 2016, 23, 94-104. [CrossRef]

65. Agarana, M.C.; Bishop, S.A.; Agboola, O.O. Minimizing carbon emissions from transportation projects in Sub-saharan Africa cities using mathematical model: A Focus on Lagos, Nigeria. Procedia Manuf. 2017, 7, 596-601. [CrossRef]

66. Chen, W.Y. The role of urban green infrastructure in offsetting carbon emissions in 35 major Chinese cities: A nationwide estimate. Cities 2015, 44, 112-120. [CrossRef]

67. Gauvillé, P.; Foucher, J.C.; Moreau, D. Achievable combustion efficiency with Alstom CFB boilers for burning discarded coal. J.S. Afr. Inst. Min. Metall. 2012, 112, 437-447.

68. Spencer, R.W.; Braswell, W.D. On the misdiagnosis of surface temperature feedbacks from variations in Earth's radiant energy balance. Remote Sens. 2011, 3, 1603-1613. [CrossRef] 
69. Dihkan, M.; Karsli, F.; Guneroglu, A.; Guneroglu, N. Evaluation of surface urban heat island (SUHI) effect on coastal zone: The case of Istanbul Megacity. Ocean Coast. Manag. 2015, 118, 309-316. [CrossRef]

70. Ranagalage, M.; Dissanayake, D.; Murayama, Y.; Zhang, X.; Estoque, R.C.; Perera, E.; Morimoto, T. Quantifying surface urban heat island formation in the world heritage tropical mountain city of Sri Lanka. ISPRS Int. J. Geo-Inf. 2018, 7, 341. [CrossRef]

71. United Nations (UN). Transforming Our World: The 2030 Agenda for Sustainable Development; United Nations General Assembly: New York, NY, USA, 2015; Volume 16301, pp. 1-35.

72. Galagoda, R.U.; Jayasinghe, G.Y.; Halwatura, R.U.; Rupasinghe, H.T. The impact of urban green infrastructure as a sustainable approach towards tropical micro-climatic changes and human thermal comfort. Urban For. Urban Green. 2018, 34, 1-9. [CrossRef]

(C) 2018 by the authors. Licensee MDPI, Basel, Switzerland. This article is an open access article distributed under the terms and conditions of the Creative Commons Attribution (CC BY) license (http:/ / creativecommons.org/licenses/by/4.0/). 